\title{
Neurophysiological and behavioral evidence that self-uncertainty salience increases self-esteem striving
}

\author{
Qing Yang ${ }^{\mathrm{a}, \mathrm{b}, *}$, Oscar Ybarra ${ }^{\mathrm{c}}$, Kees Van den $\operatorname{Bos}^{\mathrm{d}}$, Yufang Zhao ${ }^{\mathrm{b}, * *}$, Lili Guan ${ }^{\mathrm{e}}$, Yunfei Cao ${ }^{\mathrm{f}}$, \\ Fang $\mathrm{Li}^{\mathrm{g}}$, Xiting Huang ${ }^{\mathrm{b}, * *}$ \\ ${ }^{a}$ Faculty of Education, Qufu Normal University, Qufu, China \\ ${ }^{\mathrm{b}}$ Key Laboratory of Cognition and Personality, Ministry of Education, School of Psychology, Southwest University, Chongqing, China \\ ${ }^{\mathrm{c}}$ Department of Psychology, University of Michigan, Ann Arbor, USA \\ ${ }^{\mathrm{d}}$ Department of Social and Organizational Psychology, Utrecht University, Utrecht, Netherlands \\ ${ }^{\mathrm{e}}$ School of Psychology, Northeast Normal University, Changchun, China \\ ${ }^{\mathrm{f}}$ College of Teachers, Chengdu University, Chengdu, China \\ ${ }^{\mathrm{g}}$ School of Teacher Education, Taishan University, Taian, China
}

\section{A R T I C L E I N F O}

\section{Keywords:}

Self-uncertainty

Self-esteem

Performance monitoring

Error positivity

Error-related negativity

Meaning maintenance model

\begin{abstract}
A B S T R A C T
The present research investigated the effect of self-uncertainty salience on self-esteem striving, as well as the corresponding self-regulatory processes. Inspired by uncertainty management and meaning maintenance models, we conducted an electroencephalogram experiment to examine how self-uncertainty salience affects performance on self-esteem related tasks, and how it affects neurophysiological activity related to performance monitoring (e.g., error-related negativity, error positivity) on those tasks. Results showed that when self-uncertainty was salient, participants performed better on a task that was high (but not low) in self-esteem relevance, and these participants also displayed a larger amplitude of error positivity after error commissions, which is considered a manifestation of heightened performance monitoring. Overall, these results suggest that self-uncertainty salience increases the need and efforts for self-esteem striving. Further implications are discussed in terms of meaning compensation and self-uncertainty management.
\end{abstract}

\section{Introduction}

We humans all come into this world with the mental machinery for creating models of how things work, that is, of ourselves and who we are, of other people, and the broader world. We impose mental structure to obtain a sense of ourselves and the things around us so that we can act and behave in meaningful ways in this world. But as the famous Greek philosopher Heraclitus (540-480 BCE) noted, "There is nothing permanent except change." In other words, despite our attempts at a stable picture of ourselves and the world, uncertainty is never too far away and constitutes an inevitable and frequent part of life.

Self-uncertainty is a subjective experience when people feel unable to predict the future (Van den Bos \& Lind, 2002), or when they experience contradictions and conflicts among their cognitions, affect, or behaviors (Hogg, 2001; McGregor, Zanna, Holmes, \& Spencer, 2001; Van den Bos, 2001). It challenges the clarity about the sense of self (Hogg, 2007), induces a feeling of inconsistency and discontinuity about one's identity (Yang, Bi, Li, \& Huang, 2017), and arouses a subjective feeling of doubt in self-views (e.g., "Who am I really?"), worldviews (e.g., social and cultural norms; "Is this social system not just?"), or core values (e.g., "Is hard work not rewarded?") (Van den Bos, 2009). Generally, people find experiences that induce uncertainty about the self to be aversive and uncomfortable (Hogg, Sherman, Dierselhuis, Maitner, \& Moffitt, 2007). It creates physiological and psychological distress (Greco \& Roger, 2003), decreases one's selfconfidence (Yang et al., 2017), and even induces a sense of meaninglessness in life (Heine, Proulx, \& Vohs, 2006).

According to the meaning maintenance model (MMM, Heine et al., 2006; Proulx \& Inzlicht, 2012), when individuals' meaning frameworks are disrupted (e.g., self-certainty framework), they will seek meaning compensation by reaffirming a different meaning framework that reinstalls meaning to themselves in this world. This explains, for example, that when people's need for certainty is disrupted they may strive to regain a sense of self-worth and self-esteem (Heine et al., 2006).

\footnotetext{
* Corresponding author at: Faculty of Education, Qufu Normal University, No.57, JingXuanXi Road, Qufu, Shandong 273165, China.

*** Corresponding authors.

E-mail addresses: yq99550@gmail.com (Q. Yang), zhaobee@swu.edu.cn (Y. Zhao), xthuang@swu.edu.cn (X. Huang).
} 
Because self-uncertainty can disrupt meaning frameworks, it can induce meaning compensation processes.

The question we ask in this study is: If individuals are led to experience self-uncertainty, will they engage in increased efforts to pursue self-esteem as meaning compensation? In this study we investigated this by comparing participants in which self-uncertainty was induced, to control participants in which self-uncertainty was not induced, and by examining behavioral performance and neurophysiological activity related to performance monitoring on a task that participants believed was or was not relevant to their self-esteem.

\subsection{Self-esteem need as meaning compensation for self-uncertainty salience}

According to the MMM, meaning is the sense that things and events in this world link to another in expected and predictable ways. Humans interact with the world through meaning frameworks and schemas such that people can only understand events, experiences, and themselves through mental representations of expected and predictable associations (Randles, Proulx, \& Heine, 2011). Otherwise, people would not feel that a "problem" exists when they encounter things that violate their expectations. Self-uncertainty violates the expected or desired relationships between cognitions and experiences (e.g., "I work hard but why don't I receive sufficient respect"), and thus about our self and our place in the world (e.g., "I wonder if this is a fair world because my hard work is not rewarded"). Thus, it induces a state of meaning disruption or meaninglessness (e.g., "I feel life is empty because regardless of what I do things do not make sense"; Heine et al., 2006; Proulx \& Inzlicht, 2012).

One central claim of the MMM is that meaning framework disruption can lead individuals to respond in a "fluid compensation" manner, whereby they try to reaffirm other meaning frameworks that are available (see also McGregor et al., 2001; Steele, 1988). Fluid compensation is domain general, such that efforts to affirm one meaning schema can decrease the arousal induced by threats in other domains (Proulx \& Heine, 2010). As different meaning frameworks are substitutable and interchangeable, the meaning disruption induced by selfuncertainty can be compensated by affirming other meaning schemas, even though these other schemas may be quite different in function, content, or consciousness (Heine et al., 2006).

The MMM suggests two domains of meaning making frameworks that are closely tied to individuals seeking and maintaining certainty about the self: belongingness and self-esteem needs. Until now, belongingness affirmation has been widely studied as a method of meaning compensation after self-uncertainty salience (for reviews, see Heine et al., 2006; Hogg, 2009; McGregor, Prentice, \& Nash, 2009; Van den Bos, 2009). However, the use of self-esteem striving as a mode of fluid compensation to counter meaning disruption due to self-uncertainty has received relatively little attention.

The self-esteem meaning framework represents how people functionally relate to the external world and how much meaning they can achieve in their lives; hence, it serves as a way of maintaining a meaningful perspective on the world (Heine et al., 2006). The MMM suggests that self-esteem striving can be an effective mechanism that restores a sense of meaning when one is threatened by self-uncertainty. We thus predict that experiencing self-uncertainty should increase efforts at self-esteem striving. For instance, people under uncertainty should try to improve their performance on a task believed to be diagnostic of important self-aspects.

\subsection{Self-regulatory process underlying self-esteem striving}

The pursuit of self-esteem involves self-regulation effort to try to achieve success, especially in domains that are important sources of esteem, such as the domains of academics, appearance, approval from others, and competition (Crocker \& Park, 2004; Crocker, Luhtanen, Cooper, \& Bouvrette, 2003). Evidence has shown that when a threat to meaning is made salient, individuals will increase self-regulation efforts (e.g., monitor and control behaviors) in important domains that can protect or enhance self-esteem. For instance, Ferraro, Shiv, and Bettman, (2005) found that following a meaning threat (e.g., mortality salience), participants made less indulgent choices in domains that were important sources of esteem, suggesting that they undertook greater self-regulation efforts to protect/enhance self-esteem. Kosloff (2010) also found that subliminal priming of death resulted in people exhibiting larger neurophysiological waveforms related to error monitoring following error commissions in an esteem-related task, and this heightened neurophysiological reactivity intensified behavioral adjustments to improve performance.

Building on the meaning maintenance model (Heine et al., 2006) and notions that mortality salience may be related to salience of selfuncertainty (Van den Bos, Poortvliet, Maas, Miedema, \& Van den Ham, 2005; see also Hohman \& Hogg, 2015), we hypothesize that self-uncertainty salience should lead to intensified self-regulation efforts in domains that are important sources of esteem, and that these efforts should lead to better performance on an esteem-relevant task. In the present study, we tested this hypothesis using a cognitive task believed or (depending on condition) not believed to reflect important sources or contingencies of self-esteem, along with examining the neurophysiological activity associated with self-regulation, which we discuss next.

\subsection{Neurophysiological activity during self-regulation}

Self-regulation is defined as people's adaptive capacity to override or adjust their responses to meet standards or attain goals (Baumeister \& Vohs, 2007; Gailliot, Schmeichel, \& Baumeister, 2006). Successful self-regulation requires motivation and monitoring (Baumeister \& Vohs, 2007). That is, if people attempt to achieve some goal, they have to enact behaviors related to those goals and track them in order to meet goal standards. Thus, people have to monitor performance frequently, otherwise performance can end up being as they did not expect. If performance is unsatisfactory, they can thus adjust their responses (e.g., thoughts, behaviors) to correspond with their goals. We would therefore expect that if people are motivated to pursue self-esteem after selfuncertainty salience, they should monitor their performance more intensely as they attempt to attain a relevant goal, in the case of this research, performing well on an esteem-relevant task. In the current research we expect to observe this self-regulatory process via two sensitive neurophysiological indicators that have been reported as relevant to performance monitoring-error-related negativity (ERN) and error positivity (Pe).

The ERN is a negative deflection in an electroencephalogram (EEG) that typically peaks within $100 \mathrm{~ms}$ after the commission of an error (Falkenstein, Hohnsbein, Hoormann, \& Blanke, 1991; Gehring, Coles, Meyer, \& Donchin, 1995). Although several competing theories (e.g., conflict monitoring theory, see Botvinick, Braver, Barch, Carter, \& Cohen, 2001; Yeung, Botvinick, \& Cohen, 2004; and reinforcement learning theory, see Holroyd \& Coles, 2002) have differing perspectives on the functional significance of the ERN, they basically agree that the ERN functions as an "alarm" after error commission and signals the need for increased cognitive control and the need to make behavioral adjustments (Botvinick et al., 2001; Gehring, Goss, Coles, Meyer, \& Donchin, 1993; Holroyd \& Coles, 2002; Holroyd \& Yeung, 2012).

Recent perspectives also propose a potential motivational underpinning of the ERN (cf. Weinberg, Riesel, \& Hajcak, 2012). The ERN is sensitive to the motivational salience of errors such that the ERN is higher in people with a heightened sensitivity to the uncertainty of errors (e.g., high intolerance of uncertainty people; Baldwin, Whitford, \& Grisham, 2017; Jackson, Nelson, \& Hajcak, 2016). The ERN is also enhanced when errors are made more aversive by uncertain contexts (Jackson, Nelson, \& Proudfit, 2015; Speed, Jackson, Nelson, Infantolino, \& Hajcak, 2017), when errors are linked to incentives (e.g., punished by gain or loss; Ganushchak \& Schiller, 2008; Hajcak, Moser, 
Yeung, \& Simons, 2005; Riesel, Weinberg, Endrass, Kathmann, \& Hajcak, 2012), or when people are reminded that their performance is being evaluated by others (Hajcak et al., 2005; Kim, Iwaki, Uno, \& Fujita, 2005).

Equally important, we also examine the cognitive process of Pe, which has some disassociations with ERN. Pe is a slow positive deflection typically peaking between $200-400 \mathrm{~ms}$ following an error response (Hajcak, McDonald, \& Simons, 2003; Overbeek, Nieuwenhuis, \& Ridderinkhof, 2005; Van Veen \& Carter, 2002). Whereas ERN reflects error monitoring following both consciously and unconsciously recognized errors (Dehaene, 2018; Nieuwenhuis, Ridderinkhof, Blom, Band, \& Kok, 2001), Pe reflects only conscious error processing mechanisms such as error detection (Endrass, Reuter, \& Kathmann, 2007; Nieuwenhuis et al., 2001; Steinhauser \& Yeung, 2010) and subsequent behavioral adaptation (Overbeek et al., 2005). For example, Nieuwenhuis et al. (2001) found that participants had comparable amplitudes of ERN after erroneous saccades irrespective of whether they were consciously perceived or unperceived. In contrast, participants had significantly higher Pe after perceived compared with unperceived erroneous saccades.

Moreover, because conscious awareness of errors may induce increased motivation-related attentional allocation for compensation behaviors, some research suggests that the motivational characteristics might be more closely relevant to Pe than ERN (Kim, Marulis, Grammer, Morrison, \& Gehring, 2017; Wu et al., 2014). For example, people with stronger motivation to succeed (e.g., individuals with growth mindset vs. fixed ability mindset) have been found to show larger amplitudes of Pe after error commissions, but this was not the case for ERN (Moser, Schroder, Heeter, Moran, \& Lee, 2011).

Taken together, when applied to the present research question, we propose that if people attempt to pursue their self-esteem to counter the meaning disruption induced by self-uncertainty, they should try to perform better on an esteem-relevant task, hence they should show greater self-regulation efforts (i.e., performance monitoring) reflected in intensified ERN and Pe amplitudes on error commissions on that task. Our examination of ERN and Pe will further inform the nature (conscious or not) of these performance monitoring processes.

\subsection{The present research}

The present research explores how self-uncertainty salience affects self-esteem striving and neurophysiological activity related to performance monitoring (i.e., error monitoring). We argue that because selfuncertainty motivates people to pursue self-esteem, they should endeavor to perform well on a task (i.e., higher response accuracy) that is high (but not low) in relevance to their self-esteem (Hypothesis 1). This response set also should be manifested as heightened neurophysiological activity related to performance monitoring, indexed by elevated ERN and Pe amplitudes in response to error commissions (Hypothesis 2). Finally, if people whose uncertainties have been made salient are not offered a chance to pursue self-esteem (for example because they can only perform a task that is low in relevance to their self-esteem) then they should continue to express higher esteemstriving motivation (compared with controls) (Hypothesis 3).

To examine these hypotheses, we conducted an experiment with a 2 (uncertainty salience: self-uncertainty vs. control) $\times 2$ (self-esteem relevance: high vs. low) between-subjects design. In the experiment, half of the participants completed a self-uncertainty salience manipulation, the other half of participants were given control materials. And participants performed a task they were led to believe was either high (high esteem-relevant condition) or low (low esteem-relevant condition) in relevance to their self-esteem. EEG was recorded during this task and below we explain how we induced the uncertainty salience and self-esteem relevance manipulations.

\section{Methods}

\subsection{Participants}

For recruiting participants, we conducted an online survey in the psychology participant pool at Southwest University in China. The phrasing-modeled the Contingencies of Self-Worth Scale (Crocker et al., 2003), which was measured in this survey. Some other scales were also used in the survey so that participants could not derive the study intentions. Following Kosloff (2010), we selected participants based on their responses to two scales measuring self-esteem contingencies for academic competence and interpersonal relationship success, respectively. Each scale contained five items. For example, the academic competence scale (Cronbach's $\alpha=0.84$ ) read "My sense of self-worth is influenced by my academic performance." An item from the interpersonal relationship success scale (Cronbach's $\alpha=0.76$ ) read "My sense of self-worth depends on how successfully I connect with others." Items were rated on 7-point Likert scales $(1=$ strongly disagree; $7=$ strongly agree). They were invited to participate if their mean scores were above 4.5 on both scales (slightly above the midpoints or higher; cf. Kosloff, 2010), indicating that both of these domains were important sources of self-esteem for our participants.

Sample size was determined by a power analysis based on related research (e.g., Ben-Ari, Florian, \& Mikulincer, 1999; Hohman \& Hogg, 2015; Hohman, Gaffney, \& Hogg, 2017; Kosloff, 2010). The effect sizes of the interaction of uncertainty salience $\times$ self-esteem relevance on behavioral and EEG indices were estimated by previous well-powered studies which examined similar topics with related designs. For example, research testing the interaction effect of meaning threat $x$ compensation strategy (e.g., self-uncertainty salience $\times$ group prototypicality, or mortality salience $\times$ self-esteem) on compensation reaction (e.g., group identification, driving performance) has found medium to large effect sizes $(f=0.27-0.38)$ (Ben-Ari et al., 1999; Hohman \& Hogg, 2015; Hohman et al., 2017). Furthermore, in other EEG studies, investigators have created interventions (e.g., mortality salience; meaning compensation) to influence cognitive performance and error monitoring activity (e.g., error-commission rates and ERN/Pe on Stroop/Flanker task) (Inzlicht \& Tullett, 2010; Kosloff, 2010; Legault, Al-Khindi, \& Inzlicht, 2012). In these studies, researchers also observed medium to large effect sizes $(d=0.50-0.83)$. Given this, an a priori power analysis (G*Power 3.1.9.2; Faul, Erdfelder, Buchner, \& Lang, 2009) using a medium-large effect size $(f=0.30)$ suggested that a total sample size of 90 individuals would provide a recommended 0.80 power level (Cohen, 1988).

Thus, for this study we recruited 92 students from Southwest University in China. They were randomly assigned to one of four conditions of the 2 (uncertainty salience) $\times 2$ (self-esteem relevance) design. This study adhered to the Declaration of Helsinki and was approved by the Human Research Ethics Committee of Southwest University. All participants provided written informed consent. Two participants were excluded because they did not follow the instructions and made substantial errors. This left a total of 90 participants for analyses (63 females and 27 males, mean age $=20.7$, range 17-25).

\subsection{Procedure and materials}

The task sequence is described in Fig. 1. Upon arrival, participants were hooked up for EEG recording and told they were going to take part in a series of tasks. Participants then completed practice Stroop trials (named "Back-color task"). In the high esteem-relevant condition, the cover story gave participants additional information about this task and led them to believe their performance on this task could effectively predict their academic performance and interpersonal relationship quality (both of which were important sources of their self-esteem). In the low esteem-relevant condition, participants were told only to judge background colors of different words and were not given additional 


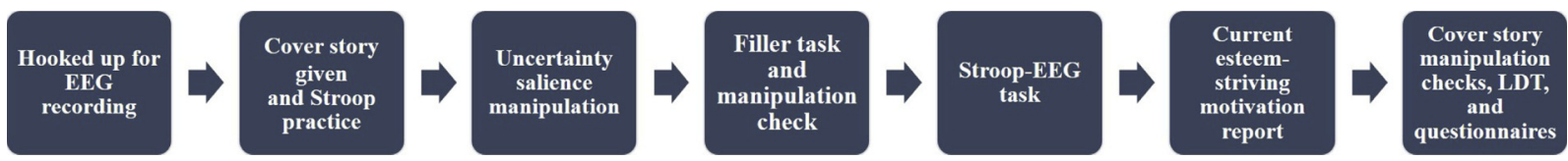

Fig. 1. The procedure of all tasks.

information.

Then participants were put through an imagination test, which in actuality was the uncertainty salience manipulation (self-uncertainty vs. control). Following the uncertainty manipulation, participants performed a filler task and uncertainty manipulation check, and then they completed the Stroop task.

After the Stroop task, participants reported their current motivation and desire for self-esteem striving. Three items (Cronbach's $\alpha=0.70$ ) were adapted from the Rosenberg (1965) self-esteem scale: "I desire to be a person of worth", "I want to be a person of competence", and "I desire to be a successful person" ( $1=$ strongly disagree, $5=$ strongly agree). Higher averaged scores indicate greater motivation for self-esteem striving at that time.

Participants then filled out the cover story manipulation checks (for the Stroop task). Participants indicated "To what extent do you agree the performance on the Back-color task could predict academic performance/interpersonal relationship quality" ( $1=$ strongly disagree, 5 $=$ strongly agree). Higher scores indicate that participants more strongly believed the predictive quality of the task, ensuring it was relevant to their self-esteem.

Finally, for exploratory purposes, participants completed a computerized lexical decision task (LDT; see detailed procedure in Supplementary Materials; cf. Kosloff, 2010) to assess the cognitive accessibility of uncertainty related thoughts. Participants also completed other questionnaires, including Rosenberg (1965) Self-Esteem Scale (Cronbach's $\alpha=0.88$; e.g., "I feel that I have a number of good qualities"; running from 1 "strongly disagree" to 4 "strongly agree"), SelfConcept Clarity Scale (Cronbach's $\alpha=0.82$; e.g., "My beliefs about myself often conflict with one another"; running from 1 "not at all characteristic of me" to 4 "entirely characteristic of me"; Campbell et al., 1996; revised by Fang, Yuan, Cao, \& Xie, 2012), and Intolerance of Uncertainty Scale (Cronbach's $\alpha=0.92$; e.g., "Uncertainty makes life intolerable"; running from 1 "not at all characteristic of me" to 5 "entirely characteristic of me"; Buhr \& Dugas, 2002; revised by Dai, Zhang, \& Liu, 2013). Higher total scores (reverse-scored items are converted) represent higher trait levels of self-esteem, self-concept clarity, and intolerance of uncertainty. After completing these questionnaires, participants were thanked and debriefed.

\subsubsection{Self-uncertainty and control groups}

The uncertainty priming procedure was taken from previous research (e.g., Bal \& Van den Bos, 2012; Hogg et al., 2007; McGregor et al., 2001; Van den Bos, 2001). In the self-uncertainty condition, participants were asked to think about those aspects that made them feel uncertain about themselves, their lives, or their futures. The detailed instruction was as follows:

There are a lot of events or experiences that may make you feel uncertain in life, those things that can often make you feel confused, that things are unpredictable, or you're in a dilemma. For example, in the relationship domain, there may have been some events that make you feel uncertain when you interact with your family, mate, friends, teachers, classmates and so on; in the academic domain, you may feel uncertain when you study, take exams, select majors, join student activities and so on; in the future plans domain, you may feel uncertain when you choose to further study or work, think about what kind of work to apply for, and what goals to set for your career; in the selfviews domain, you may feel uncertain about yourself (e.g., Am I charming or not? Smart or not? Confident or not? Mature or not?), and about your beliefs (e.g., Will good people be rewarded? Is the world fair?). Of course, there may be other aspects that make you feel uncertain. Please think about those aspects that make you feel uncertain, and answer the questions listed below.

Next, they were asked to write down three aspects that made them feel most uncertain, and to pick one of them and to describe it in detail (e.g., Bal \& Van den Bos, 2012; Hogg et al., 2007). Then, they were asked to write briefly about the emotional and physical responses they had when they felt uncertain (Van den Bos, 2001).

In the control condition participants were asked questions in a similar format about the regular things they experienced in daily life (e.g., Bal \& Van den Bos, 2012; Hogg et al., 2007), and the emotional and physical responses they had when they took a walk at school (cf. Van den Bos, 2001). Notably, in order to avoid participants thinking about aspects related to core self-views or worldviews (values), we asked them to think about aspects that made them feel normal, such as living habits and routine activities (e.g., school and rest schedules, food preferences). The instruction was as follows:

There are a lot of events or experiences that may make you feel regular in life, those things that can often make you feel normal, that things are predictable, and controllable. For example, in the living habits domain, you may feel regular about your habits on what time to go to bed, get up and wash, what food and sports you like, and what routes you always take; in the study activities domain, you may feel certain about what time and where to have classes, self-study, and joining extracurricular activities; in the social life domain, you may feel familiar about the rules in interpersonal communication, social etiquette, traffic safety, and so on. Of course, there may be other aspects that make you feel regular. Please think about those aspects that make you feel regular, and answer the questions listed below.

\subsubsection{Filler task and uncertainty manipulation check}

Participants completed a Chinese version of the Positive and Negative Affect Schedule (PANAS; Watson, Clark, \& Tellegen, 1988) as a filler task and as a way to test if the uncertainty manipulation aroused positive and negative affect. The PANAS consists of 10 positive affect items (PA, Cronbach's $\alpha=0.84$ ) and 10 negative affect (NA, Cronbach's $\alpha=0.89$ ) items. The participants rated the items on a scale ranging from 1 (very slightly) to 5 (extremely).

Then, following McGregor et al. (2001), participants indicated their current uncertainty related feelings (from $1=$ very slightly to $5=e x$ tremely) in response to the terms, "confused", "unsure" and "conflicted" (Cronbach's $\alpha=0.85$ ).

\subsubsection{The Stroop task and EEG recording and processing}

During the Stroop task, continuous EEG was recorded (see Supplementary Materials for EEG recording and processing). Stroop tasks are frequently used in EEG studies when investigating error detection or performance monitoring activities (e.g., Hajcak, McDonald, \& Simons, 2004; Hirsh \& Inzlicht, 2010; Inzlicht, McGregor, Hirsh, \& Nash, 2009; Inzlicht \& Tullett, 2010; Nash, Inzlicht, \& McGregor, 2012). Following previous research, we used a standard color-naming Stroop task, which consisted of a series of color words (e.g., "red", "yellow", "blue", "green", each in Chinese). Each of the words was presented in a font-color that either matched (congruent, 96 trials) or mismatched the word meaning (incongruent, 192 trials). Participants were asked to press the corresponding button to judge the font-color of each word quickly and accurately.

For each trial, as shown in Fig. 2, a fixation cross ("+ ") appeared for $1000 \mathrm{~ms}$, and then the color word was presented for $200 \mathrm{~ms}$. 


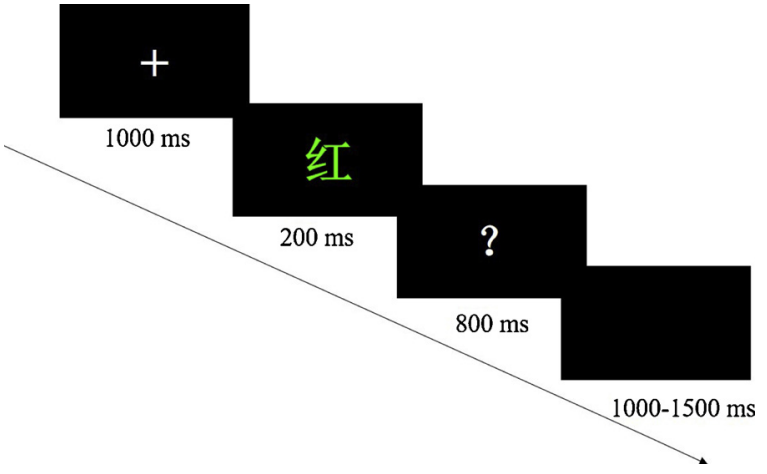

Fig. 2. An incongruent trial example ("red" in green font-color) in one of the four blocks (For interpretation of the references to colour in this figure legend, the reader is referred to the web version of this article).

Participants had at most $800 \mathrm{~ms}$ to respond, followed by a 1000-1500 ms blank screen that served as the inter-trial interval. Each block had 72 trials (24 congruent, 48 incongruent), and each participant completed four blocks with a 1 min break between each block. Thus, there were 288 trials in total for each participant (similar trials numbers used in well powered research such as Hirsh \& Inzlicht, 2010; Inzlicht et al., 2009; Nash et al., 2012; Senderecka, Kossowska, Sekerdej, \& Szewczyk, 2019). This task lasted around 15-20 min.

\section{Results}

\subsection{Manipulation checks}

We first assessed if the self-esteem relevance manipulation was successful. We predicted that participants in the high esteem-relevant condition would believe more strongly than those in the low esteemrelevant condition that the Stroop task could predict academic performance/interpersonal relationship quality. We performed a Mixed factor ANOVA, with uncertainty salience and self-esteem relevance as between-subject factors, and quality (academic vs. relationship) as a within-subject factor. The main effect of quality was significant indicating that participants generally scored higher on interpersonal relationship $(M=3.18, S E=0.08)$ than academic performance $(M=$ 2.90, $S E=0.09), F(1,86)=7.94, p=0.006, \eta^{2}=0.085$.

More importantly, the main effect of self-esteem relevance was significant such that participants in the high relevant condition $(M=$ $3.39, S E=0.11$ ) scored significantly higher than those in the low relevant condition $(M=2.68, S E=0.10), F(1,86)=24.14, p<0.001$, $\eta^{2}=0.219$. No other effects were significant.

These results indicate that participants in the high relevant condition believed more strongly than those in the low relevant condition that they would participate in a task evaluating potential success in domains deemed as important sources of their self-esteem. Thus, our manipulation of self-esteem relevance was successful.

We then checked if the uncertainty salience manipulation was successful. Typical answers given in the self-uncertainty condition had to do with participants' confusion about unsettled choices and selfviews (e.g., "I feel uncertain if I should choose to study further after graduation" and "I am not sure if I am a confident person"). In the control condition, typical answers were about participants' thoughts about their habits and routines (e.g., "I usually go to bed before 12 o'clock" and "I usually buy fruit every Tuesday at noon"). We checked all the responses from the control condition and confirmed that most of them were about participants' habits and routines in daily life, not related to important self-views (e.g., "who I am"), worldviews (e.g, "what I believe in"), or core values (e.g, "what I value most"). These results validate that the condition served as a neutral comparison compared with the self-uncertainty condition.
We averaged participants' responses to their reported feelings composed of responses to the words "confused", "unsure" and "conflicted" (Cronbach's $\alpha=0.85$ ) (following McGregor et al., 2001), and submitted the averaged scores to a $2 \times 2$, uncertainty salience by selfesteem relevance, ANOVA. There was only a significant main effect of uncertainty salience, $F(1,86)=14.54, p<0.001, \eta^{2}=0.145$. Participants in the self-uncertainty condition $(M=2.95, S E=0.15)$ felt more uncertain than participants in the control condition $(M=2.14$, $S E=0.15$ ). Thus, our manipulation of uncertainty salience was successful.

\subsection{PANAS checks}

To measure if the experimental manipulations aroused positive or negative affect (PA or NA), we performed a Mixed factor analysis of variance (ANOVA), with uncertainty salience and self-esteem relevance as between-subject factors, and type of affect (PA vs. NA) as a withinsubject factor, with the level of affect as the dependent measure. We found two significant main effects showing that PA $(M=3.07$, $S E=0.07)$ was significantly higher than NA $(M=1.97, S E=0.07), F$ $(1,86)=128.94, p<0.001, \eta^{2}=0.600$. Furthermore, participants in the self-uncertainty condition $(M=2.63, S E=0.07)$ reported higher affect levels than those in the control condition $(M=2.41, S E=0.07)$, $F(1,86)=5.16, p=0.026, \eta^{2}=0.057$. Moreover, there was a significant affect type $\times$ uncertainty salience interaction, $F(1,86)=6.75$, $p=0.011, \eta^{2}=0.073$. Simple effect analysis revealed that the selfuncertainty condition $(M=2.20, S E=0.10)$ reported significant higher level of NA (but equal PA) than the control condition ( $M=1.73$, $S E=0.10), F(1,86)=10.88, p=0.001, \eta^{2}=0.112$. No other significant effects were found.

The results suggest that the salience of self-uncertainty induced more negative feelings. Negative feelings are of course uncomfortable and at times even aversive. But self-uncertainty is thought to be a unique feeling that is distinct from a generally negative mood (Yang et al., 2017). Thus, we believe the effect of self-uncertainty salience on selfesteem striving cannot be accounted for just by negative mood. Thus, we preclude this alternative explanation by including NA as covariate in the main analyses.

\subsection{Did self-uncertainty salience improve performance on a high esteem- relevant task?}

To examine if self-uncertainty salience improved behavioral performance on a task that has implications for self-esteem (Hypothesis 1), we calculated total accuracy (proportion of correct trials from all trials), post-correct accuracy (proportion of correct trials from all trials that occurred after correct responses), and post-error accuracy (proportion of correct trials from all trials that occurred after error responses) as performance indices (see Table 1 for their correlations). Then we ran 2 (uncertainty salience) $\times 2$ (self-esteem relevance) ANOVAs. Table 2 reports the means $(M s)$ and standard deviations $(S D s)$. Since there was no gender effect in any of the main analyses, data from women and men were combined in the following analyses.

\subsubsection{Total accuracy}

For total accuracy, the main effect of uncertainty salience was significant. This effect showed that participants in the self-uncertainty condition $(M=0.90, S E=0.01)$ performed significantly better than those in the control condition $(M=0.86, S E=0.01), F(1,86)=6.88, p$ $=0.010, \eta^{2}=0.074$.

More importantly, the interaction effect of uncertainty salience $x$ self-esteem relevance was also significant, $F(1,86)=4.67, p=0.033$, $\eta^{2}=0.051$. Simple effect analyses revealed that in the high esteemrelevant condition, participants in the self-uncertainty condition $(M=$ 0.91, $S E=0.01)$ performed significantly better than control participants $(M=0.84, S E=0.01), F(1,86)=10.74, p=0.002, \eta^{2}=0.111$. 
Table 1

Bivariate correlations between behavioral variables and ERPs (Event-related potentials) components.

\begin{tabular}{|c|c|c|c|c|c|c|c|c|c|c|c|}
\hline & 1 & 2 & 3 & 4 & 5 & 6 & 7 & 8 & 9 & 10 & 11 \\
\hline 1. total accuracy & - & & & & & & & & & & \\
\hline 2. post-correct accuracy & $.985^{\text {****k }}$ & - & & & & & & & & & \\
\hline 3. post-error accuracy & $.641^{* * * * x}$ & $.541^{* * * *}$ & - & & & & & & & & \\
\hline 4. correct trials RT & .049 & .086 & -.070 & - & & & & & & & \\
\hline 5. error trials RT & .179 & $.192^{\dagger}$ & -.003 & $.809^{* * *}$ & - & & & & & & \\
\hline 6. post-correct RT & .076 & .114 & -.053 & $.997^{* * * *}$ & $.806^{* * * *}$ & - & & & & & \\
\hline 7. post-error RT & .059 & .085 & -.044 & $.810^{* * * *}$ & $.722^{* * * * *}$ & $.787^{* * * *}$ & - & & & & \\
\hline 8. ERN & -.151 & $-.180^{\dagger}$ & -.006 & -.067 & -.133 & -.061 & $-.275^{* *}$ & - & & & \\
\hline 9. CRN & .000 & -.049 & .074 & $-.184^{\dagger}$ & -.109 & $-.178^{\dagger}$ & $-.262^{*}$ & $.476^{* * * *}$ & - & & \\
\hline 10. $\mathrm{Pe}$ & .122 & .090 & .145 & -.037 & -.066 & -.031 & -.105 & $.491^{* * *}$ & $.446^{k * * *}$ & - & \\
\hline 11. Pc & .004 & -.036 & .074 & -.105 & -.147 & -.090 & $-.192^{\dagger}$ & $.315^{\text {** }}$ & $.468^{\text {k****}}$ & $.633^{* * * *}$ & - \\
\hline
\end{tabular}

Note. $* * * p 0.001,{ }^{* * p} p<0.01, * p<0.05,{ }^{\dagger} p<0.1$.

In the low esteem-relevant condition, there was no significant difference between the self-uncertainty $(M=0.89, S E=0.01)$ and the control condition $(M=0.88, S E=0.01), F(1,86)=0.11, p=0.736, \eta^{2}$ $=0.001$. See Fig. 3A.

When we included NA as a covariate to control for the possible effect of negative effect on uncertainty, the main effect of uncertainty salience remained significant, $F(1,85)=8.21, p=0.005, \eta^{2}=0.088$. Moreover, the interaction remained significant and the simple effect pattern was unchanged, $F(1,85)=4.76, p=0.032, \eta^{2}=0.053$.

\subsubsection{Post-correct accuracy}

For post-correct accuracy, the main effect of uncertainty salience was significant. Participants in the self-uncertainty condition $(M=$ $0.90, S E=0.01)$ performed significantly better than those in the control condition $(M=0.86, S E=0.01), F(1,86)=6.80, p=0.011, \eta^{2}=$ 0.073 .

Moreover, the interaction effect of uncertainty salience $\times$ self-esteem relevance was also significant, $F(1,86)=5.00, p=0.028, \eta^{2}=$ 0.055. Again, self-uncertainty participants $(M=0.91, S E=0.01)$ performed significantly better than control participants $(M=0.84$, $S E=0.01)$ in the high esteem-relevant condition, $F(1,86)=11.01, p=$ $0.001, \eta^{2}=0.113$, but not in the low esteem-relevant condition $(M s=$ 0.89 vs. $0.88, S E s=0.01), F(1,86)=0.07, p=0.786, \eta^{2}=0.001$. See Fig. 3B.

When including NA as a covariate, the main effect of uncertainty salience, $F(1,85)=7.88, p=0.006, \eta^{2}=0.085$, and the interaction effect were unchanged, $F(1,85)=5.07, p=0.027, \eta^{2}=0.056$.

\subsubsection{Post-error accuracy}

For post-error accuracy, there was only a marginally significant interaction effect of uncertainty salience $\times$ self-esteem relevance, $F$ $(1,86)=3.17, p=0.078, \eta^{2}=0.036$. Specifically, in the high esteemrelevant condition, self-uncertainty participants $(M=0.91, S E=0.02)$ performed better than control participants $(M=0.85, S E=0.02), F$ $(1,86)=4.00, p=0.049, \eta^{2}=0.044$. In the low esteem-relevant condition, there was no significant difference between the self-uncertainty $(M=0.88, S E=0.02)$ and the control condition $(M=0.89$, $S E=0.02$ ), $F(1,86)=0.22, p=0.641, \eta^{2}=0.003$ (see Fig. $3 C$ ). The interaction effect remained marginally significant after controlling for NA, $F(1,85)=3.21, p=0.077, \eta^{2}=0.036$.

In general, these results show that self-uncertainty condition participants performed better than controls, but only on a task that was relevant to their self-esteem. This finding is consistent with our hypothesis, indicating that self-uncertainty salience increases the motivation for self-esteem striving, thus improving performance on a relevant task.

Moreover, for exploratory purposes, we also computed reaction times (RTs) on correct and error trials, and on post-correct trials and post-error trials. These correlations are shown in Table 1, and the Ms and SDs are listed in Table 2. First, to measure if the experimental manipulations affected RTs on correct and error trials, we performed a Mixed factor ANOVA, with uncertainty salience and self-esteem relevance as between-subject factors, and trial type (correct vs. error) as a within-subject factor. The only significant effect was the main effect of trial type, showing that participants responded faster on correct trials

Table 2

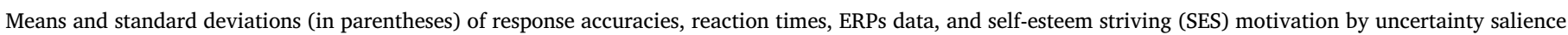
and self-esteem relevance.

\begin{tabular}{|c|c|c|c|c|}
\hline \multirow[t]{2}{*}{ Measures } & \multicolumn{2}{|l|}{ High esteem-relevant } & \multicolumn{2}{|l|}{ Low esteem-relevant } \\
\hline & Self-uncertainty $(N=21)$ & Control $(N=21)$ & Self-uncertainty $(N=25)$ & Control $(N=23)$ \\
\hline \multicolumn{5}{|l|}{ Accuracies } \\
\hline total accuracy & $0.91(0.05)$ & $0.84(0.09)$ & $0.89(0.05)$ & $0.88(0.05)$ \\
\hline post-correct accuracy & $0.91(0.05)$ & $0.84(0.08)$ & $0.88(0.06)$ & $0.88(0.05)$ \\
\hline post-error accuracy & $0.91(0.09)$ & $0.85(0.12)$ & $0.87(0.08)$ & $0.89(0.09)$ \\
\hline \multicolumn{5}{|l|}{ Reaction Times (ms) } \\
\hline correct trials & $421.67(42.43)$ & $405.00(58.99)$ & $421.56(47.02)$ & $425.48(65.50)$ \\
\hline error trials & $462.38(54.75)$ & $451.81(83.71)$ & $477.32(74.38)$ & $468.17(77.68)$ \\
\hline post-correct trials & $419.62(42.23)$ & $401.62(57.16)$ & $418.48(45.78)$ & $423.83(65.80)$ \\
\hline post-error trials & $447.48(62.45)$ & $433.43(81.21)$ & $453.64(70.01)$ & $431.70(78.28)$ \\
\hline \multicolumn{5}{|l|}{ ERN $(\mu \mathrm{V})$} \\
\hline errors & $-5.86(4.51)$ & $-5.21(4.92)$ & $-5.72(4.98)$ & $-2.95(7.04)$ \\
\hline correct & $5.65(4.65)$ & $3.41(4.32)$ & $2.46(6.06)$ & $4.37(5.28)$ \\
\hline \multicolumn{5}{|l|}{$\operatorname{Pe}(\mu \mathrm{V})$} \\
\hline errors & $10.12(7.66)$ & $4.77(7.48)$ & $5.98(7.80)$ & $8.94(9.92)$ \\
\hline correct & $6.24(5.05)$ & $3.00(6.80)$ & $3.04(6.88)$ & $6.58(8.09)$ \\
\hline SES Motivation & $4.56(0.45)$ & $4.60(0.50)$ & $4.79(0.29)$ & $4.43(0.42)$ \\
\hline
\end{tabular}




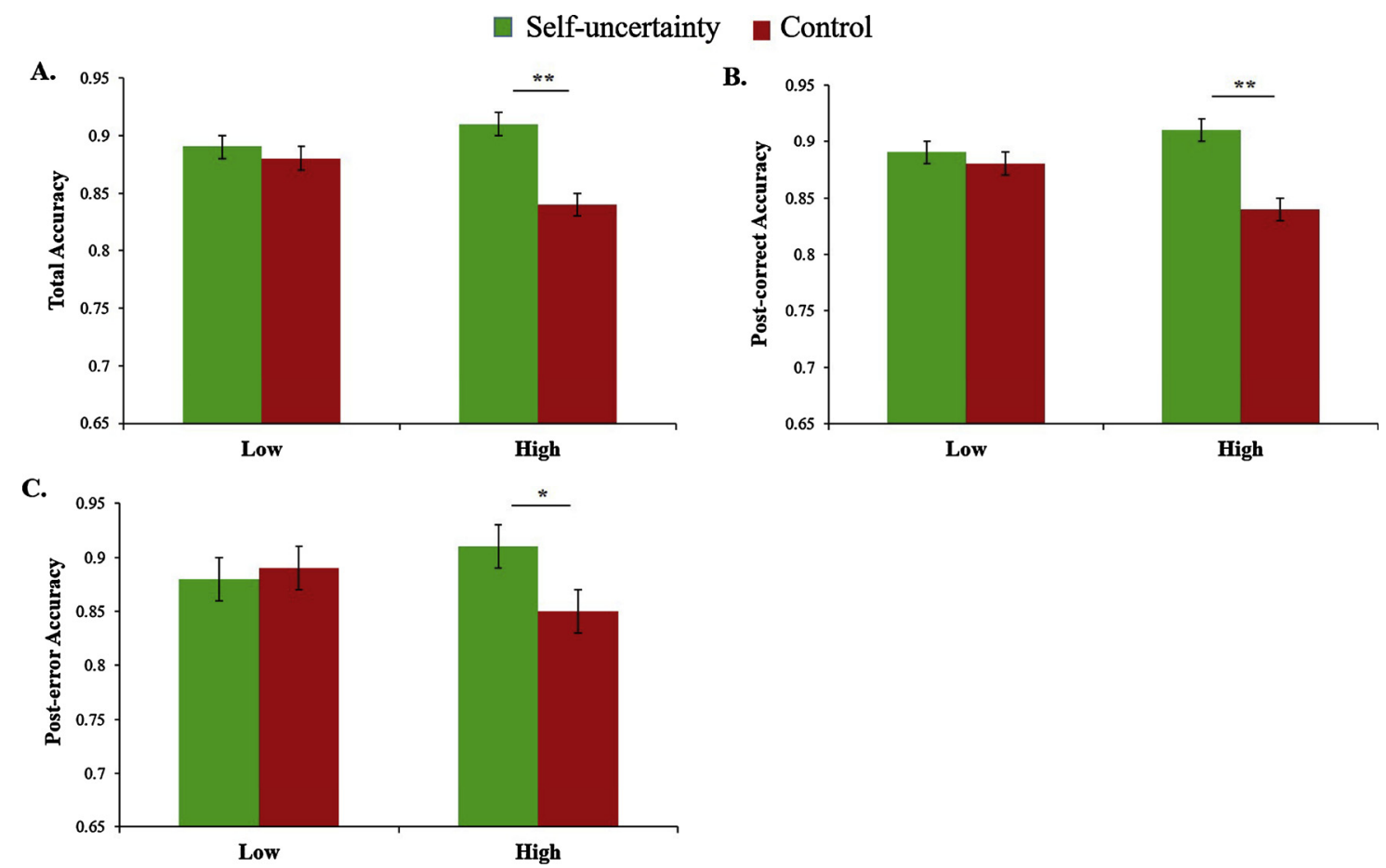

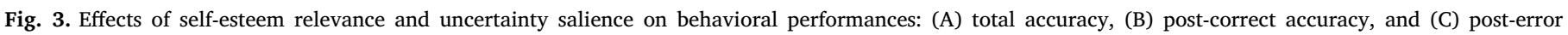
accuracy (For interpretation of the references to colour in this figure legend, the reader is referred to the web version of this article).

Error bars indicate standard error (SE). ${ }^{*} p<0.05, * * p<0.01$.

$(M=418.43 \mathrm{~ms}, S E=5.73)$ than error trials $(M=464.92 \mathrm{~ms}$, $S E=7.78), F(1,86)=102.44, p<0.001, \eta^{2}=0.544$.

To measure if the experimental manipulation affected RTs on postcorrect and post-error trials, a parallel analysis was conducted. Again, the main effect of trial type was significant, revealing that participants responded faster after correct trials $(M=415.89 \mathrm{~ms}, S E=5.66)$ than after error trials $(M=441.56 \mathrm{~ms}, S E=7.75), \quad F(1,86)=29.89$, $p<0.001, \eta^{2}=0.258$. No other effects were reliable. Overall, it appears that the experimental manipulations did not moderate RTs and only affected response accuracy.

\subsection{Did self-uncertainty salience heighten neurophysiological activity of performance monitoring on a high esteem-relevant task?}

To examine if self-uncertainty salience heightened neurophysiological activity related to performance monitoring (i.e., ERN and Pe) depending on relevance of esteem task (Hypothesis 2), we ran two Mixed factor ANOVAs: 2 (uncertainty salience: self-uncertainty vs. control) $\times 2$ (self-esteem relevance: high vs. low) $\times 2$ (response: error vs. correct) for ERN and then Pe, with the response as a within-subject factor. See Table 2 for the Ms and SDs for ERN and Pe. See Fig. 4 for ERP waveforms of correct and error trials in the four conditions. The mean number of error trials across all participants was $35.01(S D=18.7)$. As previous research justified (Olvet \& Hajcak, 2009; Senderecka et al., 2019; Steele et al., 2016), such a number of error trials is adequate to achieve a high signal-to-noise ratio and achieve stable (reliable) estimates of error-related brain activities.

\subsubsection{ERN}

The mean voltage in the window of $-25^{\sim} 75 \mathrm{~ms}$ (with $0 \mathrm{~ms}$ denoting the response) was computed as the ERN (error response) or CRN (correct response) (Weinberg et al., 2016) (see the Supplementary Materials for topographical map).

The mixed-factor ANOVA revealed a significant main effect of response indicating that the amplitude of error trials $(M=-4.93 \mu \mathrm{V}$, $S E=0.58)$ was larger than correct trials $(M=3.97 \mu \mathrm{V}, S E=0.55), F$
$(1,85)=244.60, p<0.001, \eta^{2}=0.742$.

The main effect was qualified by a response $\times$ self-esteem relevance interaction, $F(1,85)=4.12, p=0.045, \eta^{2}=0.046$. Planned contrasts indicated that the response effect was larger in the high esteem-relevant condition (mean difference $-10.06 \mu \mathrm{V}$ ) than in the low esteem-relevant condition (mean difference $-7.75 \mu \mathrm{V}$ ), though it was significant for both conditions, Fs $(1,85)>98.09$, ps $<0.001$.

Neither the interaction effect of uncertainty salience $\times$ self-esteem relevance, nor the interaction effect of uncertainty salience $\times$ self-esteem relevance $\times$ response was significant, Fs $(1,85)<2.60$, ps $>0.110$. See Fig. 5A \& B for line plots. See Fig. 6A for CRN comparisons and Fig. 6B for ERN comparisons among the four conditions.

Including NA as a covariate in the analyses did not change the significant main effect of response, $F(1,84)=23.13, p<0.001, \eta^{2}=$ 0.216 , or the significant interaction effect of response $\times$ self-esteem relevance, $F(1,84)=4.10, p=0.046, \eta^{2}=0.047$.

\subsection{2. $P e$}

The mean voltage between $250 \sim 350 \mathrm{~ms}$ after an incorrect (or correct) response was computed as the Pe (or Pc) (Andreu et al., 2017; Steinhauser \& Yeung, 2010) (see the Supplementary Materials for topographical map).

A parallel mixed-factor ANOVA found a significant main effect of response showing that the amplitude for error trials $(M=7.45 \mu \mathrm{V}$, $S E=0.88)$ was higher than for correct trials $(M=4.71 \mu \mathrm{V}, S E=0.73)$, $F(1,85)=14.38, p<0.001, \eta^{2}=0.145$.

The interaction effect of uncertainty salience $\times$ self-esteem relevance was also significant, $F(1,85)=6.83, p=0.011, \eta^{2}=0.074$. Simple effect analyses revealed that in the high esteem-relevant condition, the mean amplitude after responses (both error and correct trials) was higher in the self-uncertainty condition $(M=8.18 \mu \mathrm{V}$, $S E=1.48)$ than in the control condition $(M=3.88 \mu \mathrm{V}, S E=1.48), F$ $(1,85)=4.20, p=0.044, \eta^{2}=0.047$. In the low esteem-relevant condition, there was no significant difference between the self-uncertainty $(M=4.51 \mu \mathrm{V}, S E=1.39)$ and the control condition $(M=$ $7.76 \mu \mathrm{V}, S E=1.42), F(1,85)=2.68, p=0.105, \eta^{2}=0.031$. 
A. Uncertainty \& High Esteem-Relevant

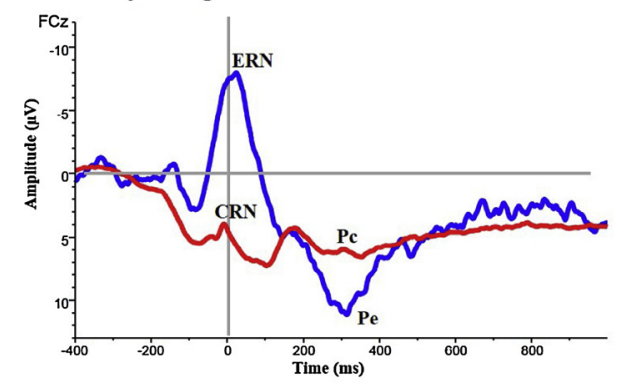

C. Control \& High Esteem-Relevant

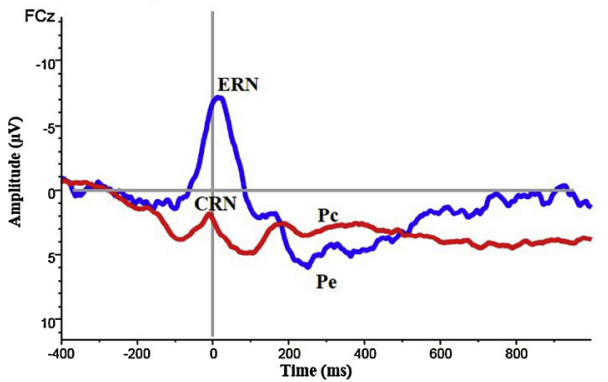

B. Uncertainty \& Low Esteem-Relevant

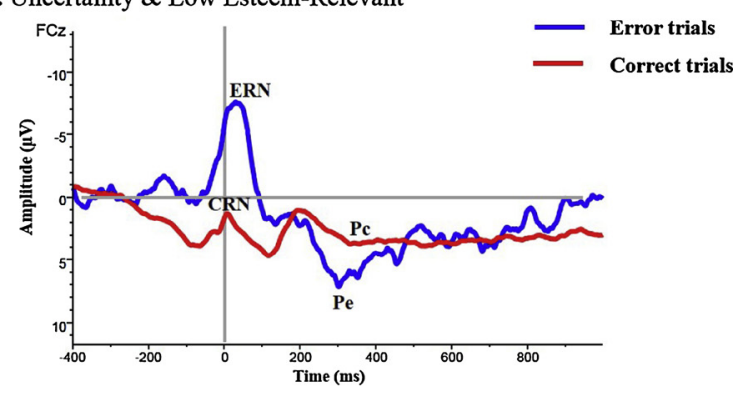

D. Control \& Low Esteem-Relevant

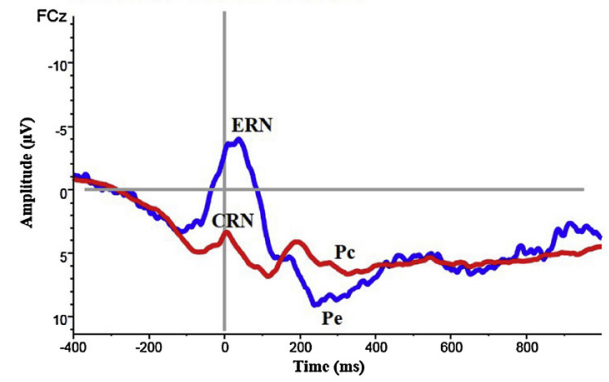

Fig. 4. Response-locked waveform amplitude at FCz following correct and error responses in the four conditions (For interpretation of the references to colour in this figure legend, the reader is referred to the web version of this article).

Further, including NA as a covariate in the analyses did not change the significant main effect of response, $F(1,84)=4.11, p=0.046, \eta^{2}=$ 0.047 , or the significant interaction effect of uncertainty salience $\times$ self-esteem relevance, $F(1,84)=7.79, p=0.006, \eta^{2}=0.085$.

A central question for the present research is whether the experimental manipulations would affect performance monitoring activity after incorrect trials, so we submitted Pe to a 2 (uncertainty salience: self-uncertainty vs. control) $\times 2$ (self-esteem relevance: high vs. low) ANOVA.

The interaction effect was significant, $F(1,85)=5.56, p=0.021, \eta^{2}$ $=0.061$. See Fig. 5C for line plots. Specifically, self-uncertainty condition $(M=10.12 \mu \mathrm{V}, S E=1.81)$ displayed significantly higher amplitude than control condition $(M=4.77 \mu \mathrm{V}, S E=1.81)$ in the high esteem-relevant condition, $F(1,85)=4.37, p=0.040, \eta^{2}=0.049$, but not in the low esteem-relevant condition $(M s=5.98 \mu \mathrm{V}$ vs. $8.94 \mu \mathrm{V}$; $S E s=1.70$ vs. 1.73$), F(1,85)=1.49, p=0.225, \eta^{2}=0.017$. See Fig. 6B for Pe waveform comparison among the four conditions. Including NA as a covariate in the analyses did not change the significant interaction effect, $F(1,84)=5.87, p=0.018, \eta^{2}=0.065$.

We also submitted Pc to the same ANOVA. Although the interaction effect was significant, $F(1,85)=5.47, p=0.022, \eta^{2}=0.060$, simple effect analyses did not reach significance, Fs $(1,85)<3.20$, $p$ s $>0.079$.

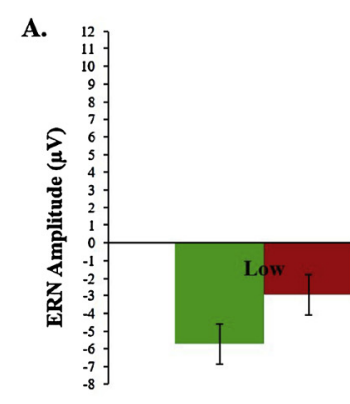

C.

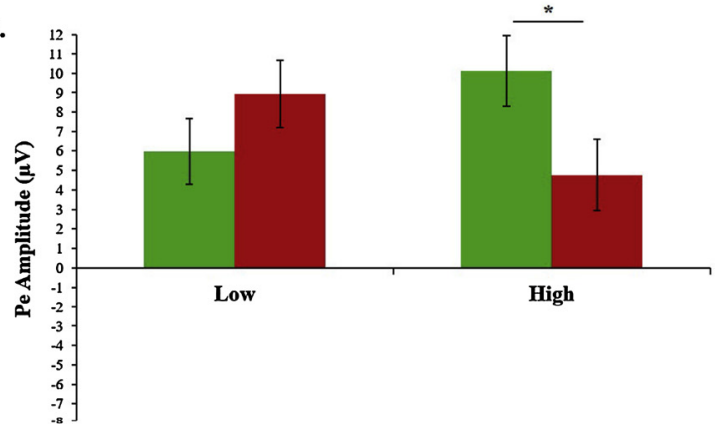

\section{Self-uncertainty Control}

B.

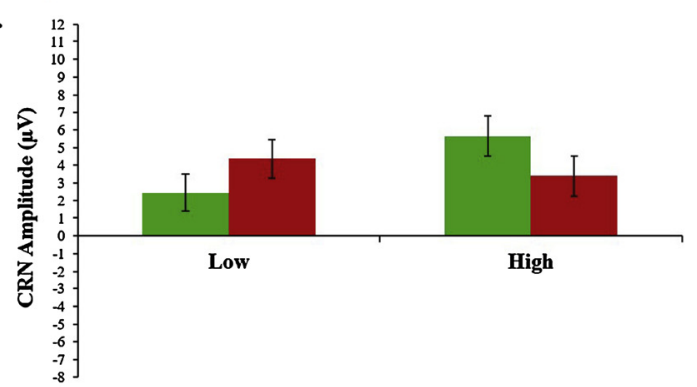

D.

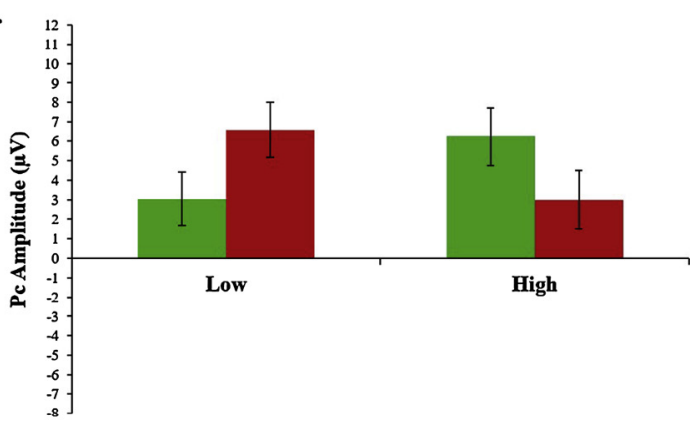

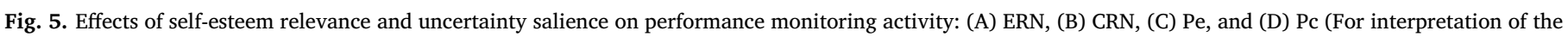
references to colour in this figure legend, the reader is referred to the web version of this article).

Error bars indicate standard error (SE). ${ }^{*} p<0.05$. 
A.

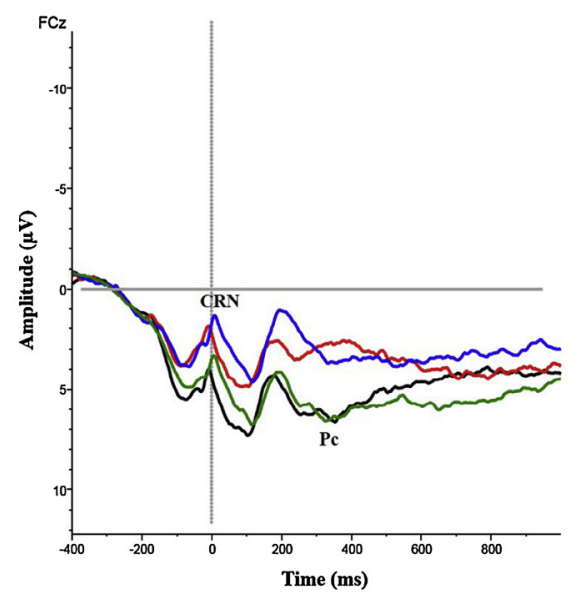

Correct trials

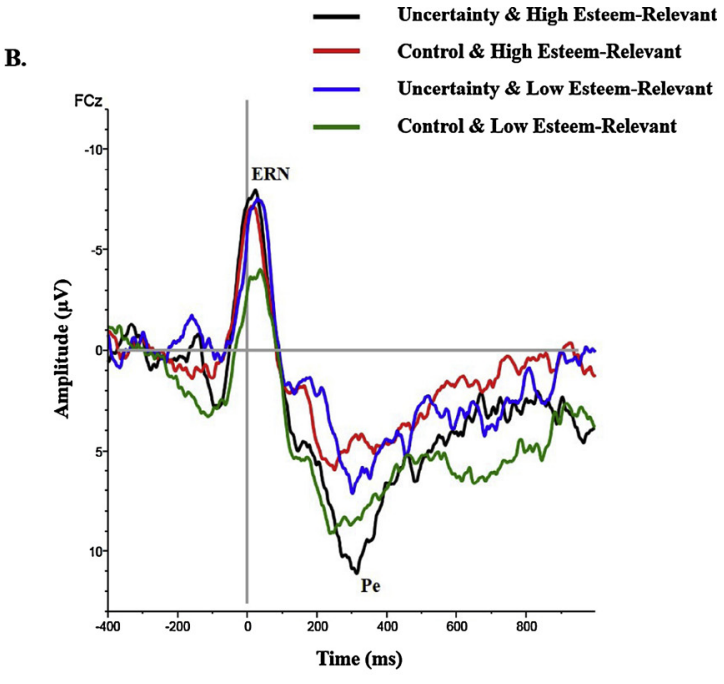

Error trials

Fig. 6. Comparison of grand-averaged waveforms among four conditions following correct trials (A) and error trials (B) (For interpretation of the references to colour in this figure legend, the reader is referred to the web version of this article).

See Figs. 5D \& 6 A. Including NA as a covariate in the analyses did not change the significance of the interaction effect, $F(1,84)=6.49, p=$ $0.013, \eta^{2}=0.072$.

Overall, self-uncertainty salience increased performance monitoring activity in response to mistakes made on a high (but not low) self-esteem relevant task, suggesting that uncertainty participants took more self-regulation (e.g., error monitoring) efforts to pursue self-esteem. Moreover, the experimental manipulation effect was salient on Pe, but not on ERN. This disassociation will be discussed in the general discussion.

\subsection{Did self-uncertainty participants report higher esteem-striving motivation after the low esteem-relevant task?}

To satisfy the need for esteem striving induced by uncertainty salience, we argued that when self-uncertainty was made salient participants would endeavor to perform well on a task that was believed to have implications for their self-esteem. However, if participants whose personal uncertainties had been made salient were not offered a chance to pursue self-esteem (as we argue was the case for those engaged in the low esteem-relevant task), they should still have the motivation to strive for self-esteem. Thus, we predicted that uncertainty participants would report higher esteem-striving motivation than the control participants after performing the low esteem-relevant task. In contrast, if the uncertainty participants have already had a chance to strive for selfesteem (on the high esteem-relevant task), they should not report additional esteem-striving motivation (compared with control participants) after performing the high esteem-relevant task. We examine this hypothesis next (Hypothesis 3).

The items to measure current levels of motivation for self-esteem striving (assessed right after the Stroop task) were averaged (Cronbach's $\alpha=0.70$ ) and submitted to a 2 (uncertainty salience) $\times 2$ (self-esteem relevance) ANOVA. See Table 2 for descriptive statistics.

As expected, the interaction effect was significant, $F(1,86)=5.14, p$ $=0.026, \eta^{2}=0.056$ (see Fig. 7). Consistent with predictions, uncertainty participants (compared with controls) expressed stronger selfesteem striving motivation when they did not previously get a chance to pursue self-esteem (i.e., on the low esteem-relevant task) ( $M \mathrm{~s}=4.79$ and 4.44, SEs $=0.08$ and 0.09), $F(1,86)=8.53, \quad p=0.004$, $\eta^{2}=0.090$, but not when they had already had the chance (i.e., on the high esteem-relevant task) ( $M s=4.56$ and 4.60, $S E s=0.09$ and 0.09), $F(1,86)=0.14, p=0.712, \eta^{2}=0.002$. Again, including NA as a

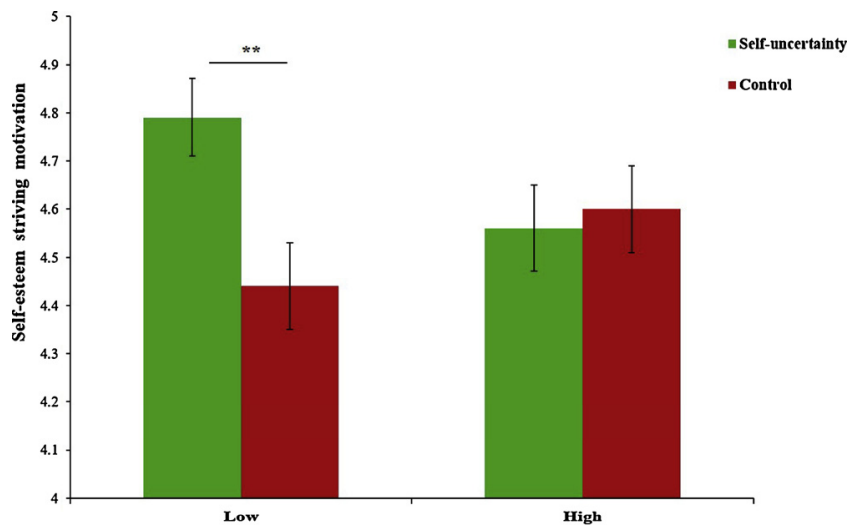

Fig. 7. Reported self-esteem striving motivation as a function of self-esteem relevance and uncertainty salience (For interpretation of the references to colour in this figure legend, the reader is referred to the web version of this article).

Error bars indicate standard error (SE). ${ }^{* *} p<0.01$.

covariate in the analyses did not change the pattern of the interaction effect, $F(1,85)=5.13, p=0.026, \eta^{2}=0.057$.

The results suggest that self-uncertainty salience did increase individuals' need for self-esteem striving. If uncertainty participants had not been offered an opportunity to pursue self-esteem, their need and motivation for esteem-striving would persist (at least for a while). Below we describe exploratory analyses relevant to this proposal.

\subsection{Exploratory analyses: uncertainty mitigation and uncertainty accessibility}

To explore if the need to strive for self-esteem could further help mitigate self-uncertainty and reduce the cognitive accessibility of uncertainty thoughts, we ran two exploratory analyses focusing on dispositional levels of self-esteem.

First, we examined if people with higher self-esteem would report lower levels of self-uncertainty. Self-concept clarity and intolerance of uncertainty are two of the three dimensions of self-uncertainty, whose structure includes cognitive (i.e. clarity about self-concept), affective (i.e. feelings about uncertainty such as intolerance of uncertainty, emotional responses to uncertainty) and motivational (i.e. motivation to solve uncertainty) dimensions (Yang et al., 2017). Results showed 


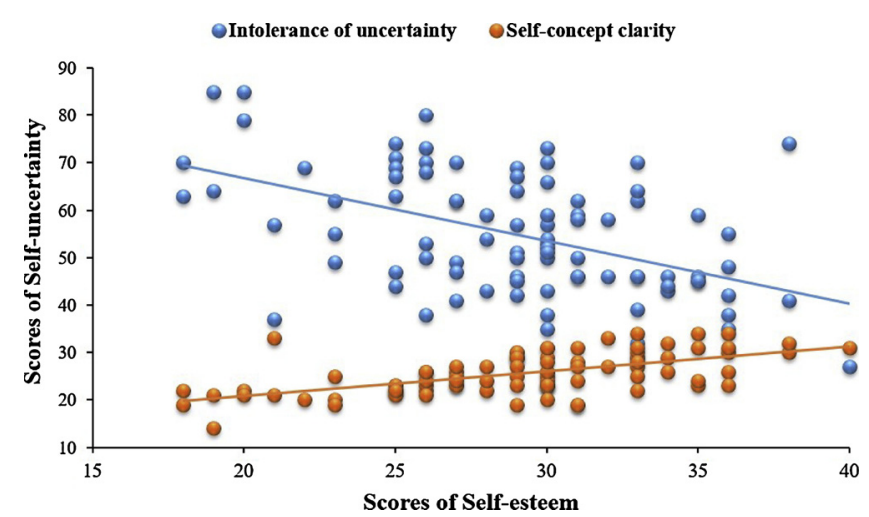

Fig. 8. Scatterplots of the relations between trait levels of self-esteem with intolerance of uncertainty (blue dots), and self-esteem with self-concept clarity (orange dots) (For interpretation of the references to colour in this figure legend, the reader is referred to the web version of this article).

that higher levels of self-esteem $(M=28.98, S D=4.77)$ significantly predicted higher levels of self-concept clarity $(M=25.43, S D=4.22)$, $\beta=0.60, t=6.99, p<0.001$, and lower levels of intolerance of uncertainty $(M=54.93, S D=13.07), \beta=-0.48, t=-5.15, p<0.001$. See Fig. 8. These significant correlations suggest that self-esteem might help to mitigate the feelings of self-uncertainty.

When we submitted these scores to a 2 (uncertainty salience) $\times 2$ (self-esteem relevance) ANOVA, no significant main effects or interaction effect were found, Fs $(1,86)<2.10$, $p s>0.150$. These results suggest that our participants did not differ on these dimensions, and any significant effect in our main results could not be accounted for by the difference of these traits. Moreover, treating these three variables as predictors of behavioral performances, ERN, Pe, and esteem-striving motivation did not produce any significant results.

Second, to explore if successful self-esteem pursuit could reduce the cognitive accessibility of uncertainty thoughts, we calculated uncertainty accessibility (i.e. RTs on uncertainty-related words; faster RTs represented more accessibility) and submitted these scores to a 2 (uncertainty salience) $\times 2$ (self-esteem relevance) ANOVA. However, no significant main effects or interaction effect were found, $F s(1,86)<1$, ps $>0.3$.

\subsection{Additional data and analyses}

Given that we did not measure state level of self-esteem after selfuncertainty salience, one may question that uncertainty salience may directly decrease state self-esteem, which possibly drove the following esteem-striving effects. To preclude this possibility, we collected additional self-report data.

First, we recruited a new comparable sample of participants ( $N=96$, mean age $=18.5$, age range 17-20) who also based their selfesteem contingencies on academic competence and interpersonal relationship success (i.e., mean scores on both scales were also slightly above the midpoints or higher). Then, following the previous procedure, participants completed the uncertainty priming procedure (using same materials), and performed the same filler task (PANAS measurements) and uncertainty manipulation check (measurements on the items of "confused", "unsure" and "conflicted", Cronbach's $\alpha=0.76$ ), and lastly completed the state self-esteem measurement using the 20Item State Self-Esteem Scale (Heatherton \& Polivy, 1991). This scale contains items such as "I feel inferior to others at this moment" (running from 1 "not at all characteristic of me" to 5 "entirely characteristic of me, Cronbach's $\alpha=0.89$ ).

The results confirmed that uncertainty salience manipulation significantly increased uncertain feelings $(M s=2.97$ and $2.35, S D s=0.99$ and 0.82), $t(94)=3.35, p=0.001, d=0.68$, but did not significantly change state self-esteem level $(M s=64.93$ and 66.21, $S D s=11.85$ and
12.93), $t(94)=-0.50, p=0.615, d=-0.10$.

Second, using a regular sample $(N=268$, participants were not categorized on scoring high or low on self-esteem contingencies) and a similar uncertainty priming procedure, our recent study (Yang, Zhao, Ybarra, Guan, \& Huang, under review) also revealed that the state selfesteem level did not significantly change as a result of the uncertainty salience manipulation $(M s=72.82$ and 73.11, $S D s=10.69$ and 10.77), $t(266)=-0.22, p=0.824, d=0.03$.

Overall, our findings are consistent with previous research (e.g., McGregor et al., 2001) supporting the idea that self-uncertainty salience does not directly decrease state self-esteem.

\section{General discussion}

Based on the MMM (Heine et al., 2006), and using online EEG, the present research examined how self-uncertainty salience affected behavioral performance and neurophysiological activity of performance monitoring on a task related to an individual's self-esteem. We provided evidence that self-uncertainty salience improved behavioral performance (i.e., response accuracies), and error monitoring activity (i.e., $\mathrm{Pe}$ ) in a high (but not low) self-esteem relevant task. Moreover, when self-uncertainty participants were not offered an opportunity to pursue their self-esteem, they expressed stronger motivation for boosting selfesteem.

These findings provide empirical support for the MMM. That is, the meaning threat induced by self-uncertainty can drive people to expend more self-regulatory effort toward affirming/pursuing other meaning frameworks, in this case, by means of self-esteem. A stronger sense of self-esteem might fluidly compensate for the meaning disruption induced by self-uncertainty. Thus, people experiencing self-uncertainty are more interested in performing a task that can support their contingencies of self-esteem compared to an esteem irrelevant task.

Our findings may contribute to a better understanding of uncertainty management through the fluid compensation of meaning maintenance. Influential theories about uncertainty management, such as the uncertainty management model (Van den Bos, 2009), uncertainty-identity theory (Hogg, 2007), and uncertainty-reactive approach motivation theory (McGregor et al., 2001), deal with how people cope with self-uncertainty mainly by defending their cultural worldviews, group identification, and compensatory convictions. These defensive responses, according to the MMM, mainly focus on the role of affiliative (belongingness) needs in the reconstruction of meaning in response to uncertainty. However, the role of self-esteem striving in managing self-uncertainty is a relatively neglected topic. The present research suggests that individuals experiencing self-uncertainty can also attempt to engage in behaviors that will provide them with a sense of self-worth to try to mitigate the uncertainty.

By performing well on a task that has implications for self-esteem, people might achieve a feeling of competence and being worthy, which is associated with a feeling of meaningfulness that helps to counter selfuncertainty. For example, people might temporarily feel they are competent and well connected with others, and these feelings are important sources of meaningfulness (i.e., when the actual performance accords with the expectation of being a valued person, this consonant relation provides meaning; cf. Heine et al., 2006), which may subsequently provide them with certainty to deal with aspects of one's life currently causing uncertainty, and also potentially have downstream effects on other aspects of psychological health. The correlation analyses provide supporting evidence that higher levels of self-esteem could help maintain the clarity of the sense of the self and help individuals better tolerate feelings of uncertainty. We expect future research to directly manipulate self-esteem level and measure its effects in mitigating the feeling of self-uncertainty.

Although we hypothesized that self-uncertainty salience should increase error monitoring activity indexed by both ERN and Pe in the high esteem-relevant task, we only observed the significant effect on Pe 
but not on ERN. Previous studies have found disassociations of Pe and ERN on a variety of research topics (Kim et al., 2017; Moser et al., 2011; Wu et al., 2014). One possible explanation might be addressed from the disassociations of the functional significances of Pe and ERN. Previous research has found that Pe is more salient after perceived than unperceived errors, and ERN is less influenced by awareness of errors (e.g., Endrass et al., 2007; Nieuwenhuis et al., 2001). Moreover, perceived errors are found to be more relevant to subsequent behavioral and neural adaptations than unperceived errors (e.g., Navarro-Cebrian, Knight, \& Kayser, 2013; Nieuwenhuis et al., 2001). Thus, Pe seems to have more motivational implications than ERN for error detection and signaling the need for subsequent self-regulation efforts (e.g., Kim et al., 2017; Steinhauser \& Yeung, 2010; Wu et al., 2014). In the present research, self-uncertainty salience might have enhanced on-line error awareness and heightened error processing after participants consciously (but not unconsciously) recognized their error commissions in the high esteem-relevant task, so that the amplitude of Pe (but not ERN) was more pronounced. But given that our design did not assess awareness of errors, we recommend future research to examine this explanation.

The present research is not without limitations. Although we found that self-uncertainty increased self-esteem striving, and that people performed better on an esteem relevant task, we did not measure the corresponding state levels of self-esteem. Thus, we cannot conclude that these effects led to an improvement on state self-esteem. Future work is recommended to examine the causal relationship between self-uncertainty, performance on an esteem-relevant task, and subsequent state levels of self-esteem, while also creating experimental situations that help pinpoint whether participants are aiming to improve their self-esteem or to prevent reductions in self-esteem (Crocker \& Park, 2004). In addition, although our exploratory analysis reveals that higher self-esteem is related to lower self-uncertainty, and may suggest that self-esteem can mitigate self-uncertainty feelings, given that this is only a correlation, together with the aforementioned point, future research is needed to provide causal evidence that higher self-esteem leads to lower self-uncertainty feelings.

\section{Coda}

The sense of self for individuals, as well as the meaning they ascribe to their actions are critically important. People always try to build models, not only of the world but also of themselves, their competencies, and where they fit in. The present research investigated the effect of self-uncertainty salience on self-esteem striving, as well as a corresponding neurophysiological mechanism underlying self-regulation. We found that uncertainty salience improved performance and heightened neurophysiological activity related to performance monitoring on a task that was believed to have implications for a person's self-esteem. We argue that people engaged in more self-regulation efforts to pursue their self-esteem in order to counter the meaning disruption induced by uncertainty salience. These findings contribute to a better understanding of the nature and effects of uncertainty-a regular experience for conscious, social beings-and suggest a potential way to manage self-uncertainty, by increasing esteem striving to strengthen performance and ultimately one's competencies.

\section{Conflict of interest statement}

The authors declare no competing financial interests.

\section{Author's note}

This article is based on the author's doctoral dissertation at Southwest University.

\section{Acknowledgments}

This work was supported by the Scientific Research Startup Project of Qufu Normal University (105-607701), the Fundamental Research Funds for the Central Universities (SWU1509113), and the National Natural Science Foundation of China (31700981).

\section{Appendix A. Supplementary data}

Supplementary material related to this article can be found, in the online version, at doi:https://doi.org/10.1016/j.biopsycho.2019.02. 011.

\section{References}

Andreu, C. I., Moënne-Loccoz, C., López, V., Slagter, H. A., Franken, I. H., \& Cosmelli, D. (2017). Behavioral and electrophysiological evidence of enhanced performance monitoring in meditators. Mindfulness, 1-12.

Bal, M., \& Van den Bos, K. (2012). Blaming for a better future: Future orientation and associated intolerance of personal uncertainty lead to harsher reactions toward innocent victims. Personality and Social Psychology Bulletin, 38, 835-844.

Baldwin, P. A., Whitford, T. J., \& Grisham, J. R. (2017). The relationship between hoarding symptoms, intolerance of uncertainty, and error-related negativity. Journal of Psychopathology and Behavioral Assessment, 39, 313-321.

Baumeister, R. F., \& Vohs, K. D. (2007). Self-Regulation, ego depletion, and motivation. Social and Personality Psychology Compass, 1, 115-128.

Ben-Ari, O. T., Florian, V., \& Mikulincer, M. (1999). The impact of mortality salience on reckless driving: A test of terror management mechanisms. Journal of Personality and Social Psychology, 76, 35-45.

Botvinick, M. M., Braver, T. S., Barch, D. M., Carter, C. S., \& Cohen, J. D. (2001). Conflict monitoring and cognitive control. Psychological Review, 108, 624-652.

Buhr, K., \& Dugas, M. J. (2002). The intolerance of uncertainty scale: Psychometric properties of the English version. Behaviour Research and Therapy, 40, 931-945.

Campbell, J. D., Trapnell, P. D., Heine, S. J., Katz, I. M., Lavallee, L. F., \& Lehman, D. R. (1996). Self-concept clarity: Measurement, personality correlates, and cultural boundaries. Journal of Personality and Social Psychology, 70, 141-156.

Cohen, J. (1988). Statistical power analysis. Hillsdale, NJ: Routledge.

Crocker, J., \& Park, L. E. (2004). The costly pursuit of self-esteem. Psychological Bulletin, 130, 392-414.

Crocker, J., Luhtanen, R. K., Cooper, M. L., \& Bouvrette, A. (2003). Contingencies of selfworth in college students: Theory and measurement. Journal of Personality and Social Psychology, 85, 894-908.

Dai, B., Zhang, G., \& Liu, H. (2013). Reliability and validity of the Chinese revised version of the intolerance of uncertainty scale. Chinese Journal of Behavioral Medicine and Brain Science, 22, 949-951.

Dehaene, S. (2018). The error-related negativity, self-monitoring, and consciousness Perspectives on Psychological Science, 13, 161-165.

Endrass, T., Reuter, B., \& Kathmann, N. (2007). ERP correlates of conscious error recognition: Aware and unaware errors in an antisaccade task. The European Journal of Neuroscience, 26, 1714-1720.

Falkenstein, M., Hohnsbein, J., Hoormann, J., \& Blanke, L. (1991). Effects of crossmodal divided attention on late ERP components. II. Error processing in choice reaction tasks. Electroencephalography and Clinical Neurophysiology, 78, 447-455.

Fang, X. Y., Yuan, X. J., Cao, H. J., \& Xie, Q. H. (2012). Psychological health diathesis assessment system: The development of general self-concept scale for Chinese adults. Studies of Psychology and Behavior, 10, 248-254.

Faul, F., Erdfelder, E., Buchner, A., \& Lang, A. G. (2009). Statistical power analyses using $G^{*}$ Power 3.1: Tests for correlation and regression analyses. Behavior Research Methods, 41, 1149-1160.

Ferraro, R., Shiv, B., \& Bettman, J. R. (2005). Let us eat and drink, for tomorrow we shall die: Effects of mortality salience and self-esteem on self-regulation in consumer choice. The Journal of Consumer Research, 32, 65-75.

Gailliot, M. T., Schmeichel, B. J., \& Baumeister, R. F. (2006). Self-regulatory processes defend against the threat of death: Effects of self-control depletion and trait selfcontrol on thoughts and fears of dying. Journal of Personality and Social Psychology, 91, 49-62.

Ganushchak, L. Y., \& Schiller, N. O. (2008). Motivation and semantic context affect brain error-monitoring activity: An event-related brain potentials study. Neuroimage, 39, 395-405.

Gehring, W. J., Coles, M. G., Meyer, D. E., \& Donchin, E. (1995). A brain potential manifestation of error-related processing. Electroencephalography and Clinical Neurophysiology-Supplements only, 44, 261-272.

Gehring, W. J., Goss, B., Coles, M. G., Meyer, D. E., \& Donchin, E. (1993). A neural system for error detection and compensation. Psychological Science, 4, 385-390.

Greco, V., \& Roger, D. (2003). Uncertainty, stress, and health. Personality and Individual Differences, 34, 1057-1068.

Hajcak, G., McDonald, N., \& Simons, R. F. (2003). To err is autonomic: Error-related brain potentials, ANS activity, and post-error compensatory behavior. Psychophysiology, 40, 895-903.

Hajcak, G., McDonald, N., \& Simons, R. F. (2004). Error-related psychophysiology and negative affect. Brain and Cognition, 56, 189-197. 
Hajcak, G., Moser, J. S., Yeung, N., \& Simons, R. F. (2005). On the ERN and the significance of errors. Psychophysiology, 42, 151-160.

Heatherton, T. F., \& Polivy, J. (1991). Development and validation of a scale for measuring state self-esteem. Journal of Personality and Social Psychology, 60, 895-910.

Heine, S. J., Proulx, T., \& Vohs, K. D. (2006). The meaning maintenance model: On the coherence of social motivations. Personality and Social Psychology Review, 10, 88-110.

Hirsh, J. B., \& Inzlicht, M. (2010). Error-related negativity predicts academic performance. Psychophysiology, 47, 192-196.

Hogg, M. A. (2001). A social identity theory of leadership. Personality and Social Psychology Review, 5, 184-200.

Hogg, M. A. (2007). Uncertainty-identity theory. In M. P. Zanna (Vol. Ed.), Advances in experimental social psychology: Vol. 39, (pp. 69-126). San Diego, CA: Academic Press.

Hogg, M. A. (2009). Managing self-uncertainty through group identification. Psychological Inquiry, 20, 221-224.

Hogg, M. A., Sherman, D. K., Dierselhuis, J., Maitner, A. T., \& Moffitt, G. (2007). Uncertainty, entitativity, and group identification. Journal of Experimental Social Psychology, 43, 135-142.

Hohman, Z. P., \& Hogg, M. A. (2015). Fearing the uncertain: Self-uncertainty plays a role in mortality salience. Journal of Experimental Social Psychology, 57, 31-42.

Hohman, Z. P., Gaffney, A. M., \& Hogg, M. A. (2017). Who am I if I am not like my group? Self-uncertainty and feeling peripheral in a group. Journal of Experimental Social Psychology, 72, 125-132.

Holroyd, C. B., \& Coles, M. G. (2002). The neural basis of human error processing: Reinforcement learning, dopamine, and the error-related negativity. Psychological Review, 109, 679-709.

Holroyd, C. B., \& Yeung, N. (2012). Motivation of extended behaviors by anterior cingulate cortex. Trends in Cognitive Sciences, 16, 122-128.

Inzlicht, M., \& Tullett, A. M. (2010). Reflecting on god religious primes can reduce neurophysiological response to errors. Psychological Science, 21, 1184-1190.

Inzlicht, M., McGregor, I., Hirsh, J. B., \& Nash, K. (2009). Neural markers of religious conviction. Psychological Science, 20, 385-392.

Jackson, F., Nelson, B. D., \& Hajcak, G. (2016). The uncertainty of errors: Intolerance of uncertainty is associated with error-related brain activity. Biological Psychology, 113, $52-58$.

Jackson, F., Nelson, B. D., \& Proudfit, G. H. (2015). In an uncertain world, errors are more aversive: Evidence from the error-related negativity. Emotion, 15, 12-16.

Kim, E. Y., Iwaki, N., Uno, H., \& Fujita, T. (2005). Error-related negativity in children: Effect of an observer. Developmental Neuropsychology, 28, 871-883.

Kim, M. H., Marulis, L. M., Grammer, J. K., Morrison, F. J., \& Gehring, W. J. (2017). Motivational processes from expectancy-value theory are associated with variability in the error positivity in young children. Journal of Experimental Child Psychology, $155,32-47$.

Kosloff, D. M. (2010). Terror-related negativity: Exploring mortality salience-induced selfregulation and its neurobiological implementation (Unpublished doctorial dissertation)The University of Arizona.

Legault, L., Al-Khindi, T., \& Inzlicht, M. (2012). Preserving integrity in the face of performance threat: Self-affirmation enhances neurophysiological responsiveness to errors. Psychological Science, 23, 1455-1460.

McGregor, I., Prentice, M. S., \& Nash, K. A. (2009). Personal uncertainty management by reactive approach motivation. Psychological Inquiry, 20, 225-229.

McGregor, I., Zanna, M. P., Holmes, J. G., \& Spencer, S. J. (2001). Compensatory conviction in the face of personal uncertainty: Going to extremes and being oneself. Journal of Personality and Social Psychology, 80, 472-488.

Moser, J. S., Schroder, H. S., Heeter, C., Moran, T. P., \& Lee, Y. H. (2011). Mind your errors: Evidence for a neural mechanism linking growth mind-set to adaptive posterror adjustments. Psychological Science, 22, 1484-1489.

Nash, K., Inzlicht, M., \& McGregor, I. (2012). Approach-related left prefrontal EEG asymmetry predicts muted error-related negativity. Biological Psychology, 91, 96-102.

Navarro-Cebrian, A., Knight, R. T., \& Kayser, A. S. (2013). Error-monitoring and posterror compensations: Dissociation between perceptual failures and motor errors with and without awareness. Journal of Neuroscience, 33, 12375-12383.

Nieuwenhuis, S., Ridderinkhof, K. R., Blom, J., Band, G. P., \& Kok, A. (2001). Errorrelated brain potentials are differentially related to awareness of response errors: Evidence from an antisaccade task. Psychophysiology, 38, 752-760.

Olvet, D. M., \& Hajcak, G. (2009). The stability of error-related brain activity with increasing trials. Psychophysiology, 46, 957-961.

Overbeek, T. J., Nieuwenhuis, S., \& Ridderinkhof, K. R. (2005). Dissociable components of error processing: On the functional significance of the Pe vis-à-vis the ERN/Ne. Journal of Psychophysiology, 19, 319-329.

Proulx, T., \& Heine, S. J. (2010). The frog in Kierkegaard's beer: Finding meaning in the threat-compensation literature. Social and Personality Psychology Compass, 4, 889-905.

Proulx, T., \& Inzlicht, M. (2012). The five "A" s of meaning maintenance: Finding meaning in the theories of sense-making. Psychological Inquiry, 23, 317-335.

Randles, D., Proulx, T., \& Heine, S. J. (2011). Turn-frogs and careful-sweaters: Nonconscious perception of incongruous word pairings provokes fluid compensation. Journal of Experimental Social Psychology, 47, 246-249.

Riesel, A., Weinberg, A., Endrass, T., Kathmann, N., \& Hajcak, G. (2012). Punishment has a lasting impact on error-related brain activity. Psychophysiology, 49, 239-247.

Rosenberg, M. (1965). Society and the adolescent self-image. Princeton, NJ: Princeton University Press.

Senderecka, M., Kossowska, M., Sekerdej, M., \& Szewczyk, J. (2019). Religious fundamentalism is associated with hyperactive performance monitoring: ERP evidence from correct and erroneous responses. Biological Psychology, 140, 96-107.

Speed, B. C., Jackson, F., Nelson, B. D., Infantolino, Z. P., \& Hajcak, G. (2017). Unpredictability increases the error-related negativity in children and adolescents. Brain and Cognition, 119, 25-31.

Steele, C. M. (1988). The psychology of self affirmation: Sustaining the integrity of the self. In L. Berkowitz (Vol. Ed.), Advances in experimental social psychology: Vol. 21, (pp. 261-302). New York: Academic Press.

Steele, V. R., Anderson, N. E., Claus, E. D., Bernat, E. M., Rao, V., Assaf, M., et al. (2016). Neuroimaging measures of error-processing: Extracting reliable signals from eventrelated potentials and functional magnetic resonance imaging. Neuroimage, 132, 247-260.

Steinhauser, M., \& Yeung, N. (2010). Decision processes in human performance monitoring. Journal of Neuroscience, 30, 15643-15653.

Van den Bos, K. (2001). Uncertainty management: The influence of uncertainty salience on reactions to perceived procedural fairness. Journal of Personality and Social Psychology, 80, 931-941.

Van den Bos, K. (2009). Making sense of life: The existential self trying to deal with personal uncertainty. Psychological Inquiry, 20, 197-217.

Van den Bos, K., \& Lind, E. A. (2002). Uncertainty management by means of fairness judgments. In M. P. Zanna (Vol. Ed.), Advances in experimental social psychology: Vol. 34, (pp. 1-60). San Diego, CA: Academic Press.

Van den Bos, K., Poortvliet, P. M., Maas, M., Miedema, J., \& Van den Ham, E.-J. (2005). An enquiry concerning the principles of cultural norms and values: The impact of uncertainty and mortality salience on reactions to violations and bolstering of cultural worldviews. Journal of Experimental Social Psychology, 41, 91-113.

Van Veen, V., \& Carter, C. S. (2002). The timing of action-monitoring processes in the anterior cingulate cortex. Journal of Cognitive Neuroscience, 14, 593-602.

Watson, D., Clark, L. A., \& Tellegen, A. (1988). Development and validation of brief measures of positive and negative affect: The PANAS scales. Journal of Personality and Social Psychology, 54, 1063-1070.

Weinberg, A., Meyer, A., Hale-Rude, E., Perlman, G., Kotov, R., Klein, D. N., et al. (2016). Error-related negativity (ern) and sustained threat: Conceptual framework and empirical evaluation in an adolescent sample. Psychophysiology, 53, 372-385.

Weinberg, A., Riesel, A., \& Hajcak, G. (2012). Integrating multiple perspectives on errorrelated brain activity: The ERN as a neural indicator of trait defensive reactivity. Motivation and Emotion, 36, 84-100.

Wu, J., Yuan, Y., Duan, H., Qin, S., Buchanan, T. W., Zhang, K., et al. (2014). Long-term academic stress increases the late component of error processing: An ERP study. Biological Psychology, 99, 77-82.

Yang, Q., Bi, C. Z., Li, L., \& Huang, X. T. (2017). Self-uncertainty: Concepts, structures, and theories. Advances in Psychological Science, 25, 1012-1024.

Yang, Q., Zhao, Y. F., Ybarra, O., Guan, L. L., \& Huang, X. T. (under review). Reconstruction of the subjective distance of autobiographical memory after self-uncertainty salience.

Yeung, N., Botvinick, M. M., \& Cohen, J. D. (2004). The neural basis of error detection: Conflict monitoring and the error-related negativity. Psychological Review, 111, 931-959. 